\title{
Preclinical study of CC223 as a potential anti-ovarian cancer agent
}

\author{
Zhenzhen Jin ${ }^{1, *}$, Huanfu Niu ${ }^{1, *}$, Xuenan Wang ${ }^{1}$, Lei Zhang ${ }^{2}$, Qin Wang ${ }^{1}$ and Aijun \\ Yang ${ }^{1}$ \\ ${ }^{1}$ Center for Reproductive Medicine, Affiliated Hospital of Jining Medical University, Jining, China \\ ${ }^{2}$ Department of Pathology and Laboratory Medicine, Clinical Microarray Core, David Geffen School of Medicine, University of \\ California Los Angeles, Los Angeles, California, USA \\ * Co-first author
}

Correspondence to: Aijun Yang, email: yajjiningmd@163.com, yajlws2017@163.com

Keywords: ovarian cancer, mTOR, CC223, signaling

Received: April 12, 2017 Accepted: April 25, $2017 \quad$ Published: May 10, 2017

Copyright: Jin et al. This is an open-access article distributed under the terms of the Creative Commons Attribution License 3.0 (CC BY 3.0 ), which permits unrestricted use, distribution, and reproduction in any medium, provided the original author and source are credited.

\section{ABSTRACT}

Aberrant activation of mTOR contributes to ovarian cancer progression. CC223 is a novel and potent $m$ TOR kinase inhibitor. The current study tested its activity against human ovarian cancer cells. We showed that CC223, at nM concentrations, inhibited survival and proliferation of established/primary human ovarian cancer cells. Further, significant apoptosis activation was observed in CC223-treated ovarian cancer cells. CC223 disrupted assembly of mTOR complex 1 (mTORC1) and mTORC2 in SKOV3 cells. Meanwhile, activation of mTORC1 and mTORC2 was almost completely blocked by CC223. Intriguingly, restoring mTOR activation by introduction of a constitutivelyactive Akt1 only partially inhibited CC223-induced cytotoxicity in SKOV3 cells. Further studies showed that CC223 inhibited sphingosine kinase 1 (SphK1) activity and induced reactive oxygen species (ROS) production in SKOV3 cells. At last, oral administration of CC223 potently inhibited SKOV3 xenografted tumor growth in nude mice. The results of this study imply that $\mathrm{CC} 223$ could be further studied as a potential anti-ovarian cancer agent.

\section{INTRODUCTION}

Ovarian cancer is one of the leading cancers among women [1-4]. The incidence of this devastating malignancy has been rising $[3,4]$. The current treatment options of ovarian cancer, including the combination of surgery and platinum-based chemotherapy, are very limited $[1,2]$. Further, it is estimated that twothird of newly-diagnosed ovarian cancers are advanced diseases, which are remarkably resistant to current treatment [5-7].

Mammalian target of rapamycin (mTOR) is the central player of the phosphatidylinositol 3-kinase (PI3K)-Akt-mTOR cascade, which is vital for malignant transformation and cancer progression [8-12]. PI3KAkt-mTOR cascade is often over-expressed and/or overactivated in human ovarian cancer, especially in clear cell carcinoma and endometrioid adenocarcinoma [13]. mTOR over-activation is associated with a number of cancerous behaviors, including cell cycle progression, cell survival, growth and proliferation, as well as metabolism, motility, angiogenesis, apoptosis-resistance, and genomic instability [8-12]. Therefore, mTOR represents potentially important therapeutic target for ovarian cancer $[14,15]$.

Growing evidences have identified at least two multi-protein mTOR complexes: mTOR complex 1 (mTORC1) and mTOR complex 2 (mTORC2) $[16,17]$. Rapamycin and its analogs (i.e. RAD001, CCI-779) are mTORC1 inhibitors, which bind to FKBP12 to partially inhibit mTORC1 (but not mTORC2) [8]. Very recent studies have developed $\mathrm{CC} 223$ as a novel, potent, selective, and orally bioavailable mTOR kinase inhibitor [18-20]. It blocks mTOR kinase activity, therefore presumably shutting of both mTORC 1 and mTORC2 [18-20]. The preclinical study tested CC223's activity against human ovarian cancer cells both in vitro and in vivo. 


\section{RESULTS}

\section{The effect of CC223 to ovarian cancer cell survival and proliferation}

To study the potential activity of $\mathrm{CC} 223$ again ovarian cancer, established ovarian cancer cell lines, SKOV3 and CaOV3 [21, 22], were treated with $\mathrm{CC} 223$ at various concentrations $(10-300 \mathrm{nM})$. MTT assay results in Figure 1A demonstrated that CC223 inhibited ovarian cancer cell survival, in a concentration-dependent manner. The IC-50s of CC223 for SKOV3 cells and $\mathrm{CaOV} 3$ cells were $64.32 \pm 5.21 \mathrm{nM}$ and $88.17 \pm 6.32 \mathrm{nM}$, respectively. On the other hand, treatment with $\mathrm{CC} 223$ at same concentration (10-300 nM) was yet non-cytotoxic to primary human ovarian surface epithelial (IOSE-80 line) cells [23] (Figure 1A). To further study the activity of CC223 in ovarian cancer cells, clonogenicity assay was performed. Treatment with CC223 (30-300 nM) potently decreased the number of viable SKOV3 colonies (Figure 1B). Further studies showed that the percentage of trypan blue positive ("dead") SKOV3 cells was significantly increased after CC223 (30-300 nM) treatment (Figure 1C). These results suggested that $\mathrm{CC} 223$ was cytotoxic to cultured human ovarian cancer cells.

Next, SKOV3 cell proliferation was also analyzed. BrdU assay results showed that $\mathrm{CC} 223$ dose-dependently inhibited SKOV3 cell proliferation, indicated by decreased BrdU ELISA OD (Figure 1D). Importantly, treatment with CC223 (100 nM) in SKOV3 cells induced increase of G1 phase cells, but decrease of S and G2-M phase SKOV3 cells, indicating G1-S arrest (Figure 1E). These results imply that CC223 inhibited SKOV3 cell proliferation. To study CC223's activity in primary human cancer cells, a total three lines of patient-derived primary ovarian cancer cells were established, which were named as " $\mathrm{OC} 1, \mathrm{OC} 2$ and OC3". Results in Figure 1F confirmed that CC223 (100 nM, 72 hours) significantly decreased survival (or MTT OD) of these primary cancer cells. CC223's sensitivity in these primary cancer cells was slightly different (Figure 1F). Collectively, these results show that $\mathrm{CC} 223$ inhibits human ovarian cancer cell survival and proliferation.

\section{The effect of CC223 on ovarian cancer cell apoptosis}

Cell apoptosis was also tested. Caspase activity assay results in Figure 2A demonstrated that $\mathrm{CC} 223$ dose-dependently activated caspase- 3 and caspase- 9 in SKOV3 cells, indicating activation of endogenous apoptosis pathway $[24,25]$. On the other hand, the activity of caspase-8, indicator of exogenous apoptosis pathway $[24,25]$, was not changed before and after $\mathrm{CC} 223$ treatment (Figure 2A). Further studies showed that $\mathrm{CC} 223$ (30-300 nM) treatment in SKOV3 cells dramatically increased the number of TUNEL positive cells (Figure 2B) and ssDNA ELISA OD (Figure 2C), again confirming apoptosis activation. Caspase apoptosis inhibitors were applied next. MTT assay results showed that the caspase-3 inhibitor z-DEVD-fmk, the caspase-9 inhibitor z-LEHDfmk as well as the pan caspase inhibitor z-VAD-fmk all inhibited CC223 (100 nM)-induced SKOV3 cell viability reduction (Figure 2D). Therefore, CC223 apparently activated caspase-dependent apoptotic cell death. In the primary human ovarian cancer cells, treatment with CC223 $(100 \mathrm{nM})$ similarly induced apoptosis activation, or TUNEL ratio increase (Figure 2E).

\section{CC223 blocks activation of mTORC1 and mTORC2 in SKOV3 cells}

CC223 is a recently-developed mTOR kinase inhibitor [18-20], its effect on mTOR activation was tested. Co-immunoprecipitation ("Co-IP") assay was applied to test the integrity of mTOR complexes. Results showed that treatment with CC223 (100 nM, 1 hour) in SKOV3 cells disrupted assembly of both mTOR-Raptor (mTORC1 complex [26]) and mTOR-Rictor (mTORC2 complex [27]) (Figure 3A). Expressions of abovementioned mTOR complex proteins were not inhibited by the CC223 treatment (Figure 3A, "Input"). Further studies showed that CC223 treatment in SKOV3 cells almost completely blocked phosphorylation ("p-") of S6K1 and S6, both are mTORC1 indicators (Figure 3B). p-Akt Ser473, the indicator of mTORC2 activation, was also largely inhibited after CC223 treatment (Figure 3B). On the other hand, p-Akt Thr-308 (Figure 3B) and p-ERK1/2 (Figure 3C) were not changed by $\mathrm{CC} 223$ treatment. Expressions of above-mentioned total kinases were not decreased by CC223 (Figure 3B and 3C). Notably, two well-known mTOR-dependent proteins, including cyclin D1 and hypoxia-inducible factor-1 $\alpha$ (HIF1 $\alpha$ ) [28-30], were also downregulated after $\mathrm{CC} 223$ treatment in SKOV3 cells (Figure 3D). These results together confirm that $\mathrm{CC} 223$ blocks mTORC1 and mTORC2 activation in SKOV3 cells.

\section{Restoring mTOR activation only partially inhibited CC223-induced cytotoxicity in SKOV3 cells}

We compared CC223's activity with other known PI3K-Akt-mTOR inhibitors. MTT assay results in Figure 4A demonstrated that $\mathrm{CC} 223$ was significantly more potent in killing SKOV3 cells than same concentration $(100 \mathrm{nM})$ of PI3K-Akt-mTOR inhibitors, including mTORC1 inhibitor rapamycin [31], the other mTOR kinase inhibitor AZD-2014 [32] and the PI3KAkt-mTOR pan inhibitor LY294002 [33]. These results suggest that $\mathrm{CC} 223$ might exert functions other than mTOR inhibition in killing SKOV3 cells. To test this hypothesis, a constitutively-active Akt1 (ca-Akt1) [12, 34] 
was introduced to SKOV3 cells (Figure 4B). ca-Akt1 completely restored activation of mTORC1 (p-S6K1) and mTORC2 (p-Akt Ser473) in CC223-treated cells (Figure 4B). Yet, ca-Akt1 only partially inhibited (but not reversed) CC223-induced SKOV3 cell death (Figure 4C) and apoptosis (Figure 4D). Therefore these results showed that restoring $\mathrm{mTOR}$ activation can only partially inhibit CC223-induced SKOV3 cell death.

\section{CC223 inhibits SphK1 and induces ROS production in SKOV3 cells}

The above results suggested that other mechanisms beside mTOR inhibition could also be involved in CC223mediated SKOV3 cell death. Growing evidences have suggested an pivotal function of sphingosine kinase 1 (SphK1) in ovarian cancer progression $[21,22,35]$. SphK1 is often over-expressed and/or sustained-activation in ovarian cancer cells, which is associated with cancer cell survival, proliferation and apoptosis-resistance [36, 37]. On the other hand, inhibition or silence of SphK1 could lead to ceramide production and cell apoptosis [36, 37]. We showed that SphK1 activity was also decreased following CC223 treatment in SKOV3 cells (Figure 5A).
Consequently, cellular ceramide level was increased (Figure 5B). Intriguingly, our results also found that reactive oxygen species (ROS) content was also increased in CC223-treated SKOV3 cells (Figure 5C). Notably, CC223-induced SphK1 inhibition, ceramide production and oxidative stress were not changed by introduction of caAkt1 (Data not shown), suggesting that these actions by CC223 were independent of mTOR inhibition. Together, CC223 inhibits SphK1 and induces ROS production in ovarian cancer cells.

\section{CC223 inhibits SKOV3 tumor growth in nude mice}

At last, the potential anti-ovarian cancer activity of CC223 in vivo was tested. SKOV3 cells were injected (s.c.) to the nude mice to establish xenograft tumors. The tumor-bearing mice were then treated with/out CC223. Tumor growth curve results in Figure 6A showed that oral administration of CC223 (15 or $50 \mathrm{mg} / \mathrm{kg}$ body weight, gavage) largely inhibited SKOV3 tumor growth in nude mice. CC223 at $50 \mathrm{mg} / \mathrm{kg}$ was more potent than $15 \mathrm{mg} / \mathrm{kg}$ in suppressing SKOV3 tumors (Figure 6A), showing a dosedependent response in vivo. Meanwhile, estimated tumor
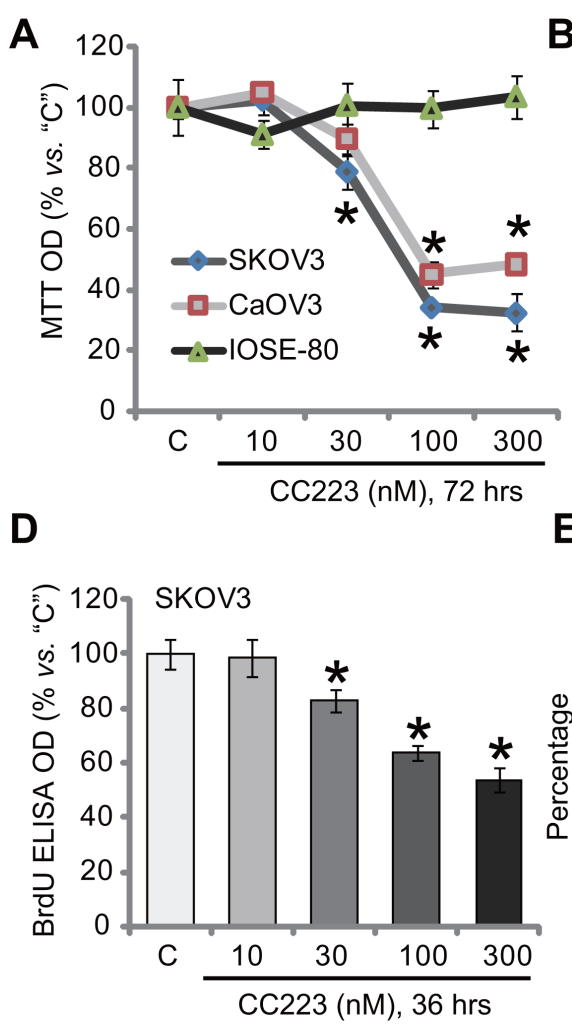

B

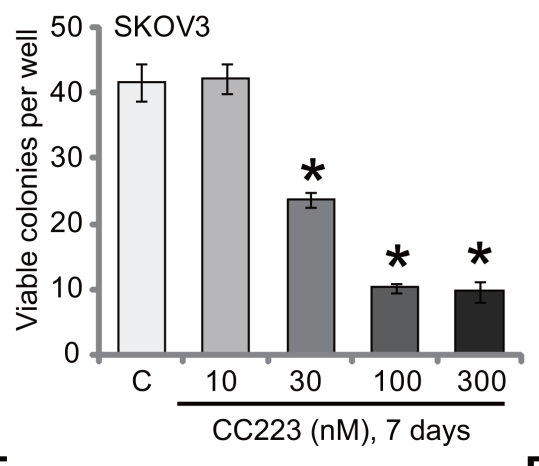

$E$

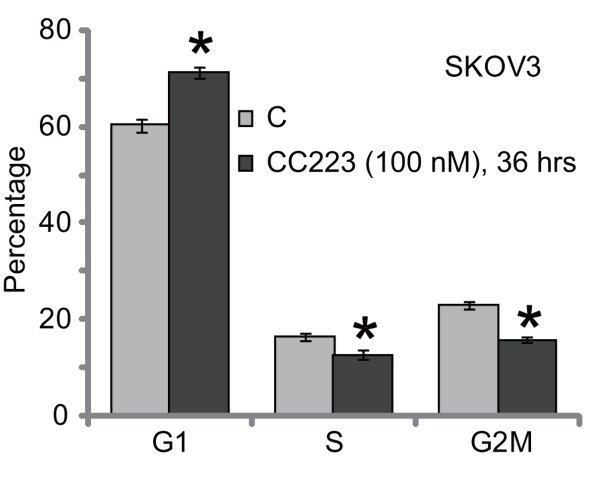

C

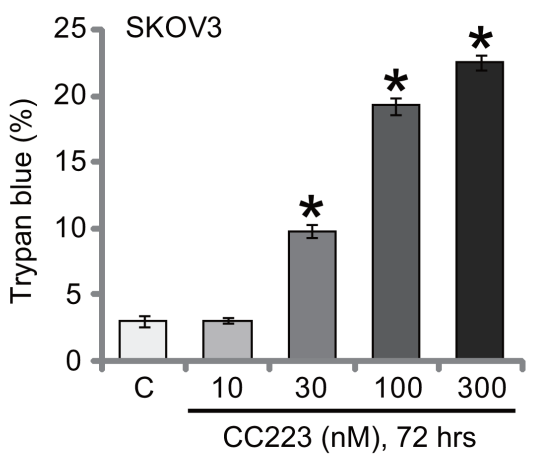

$F$

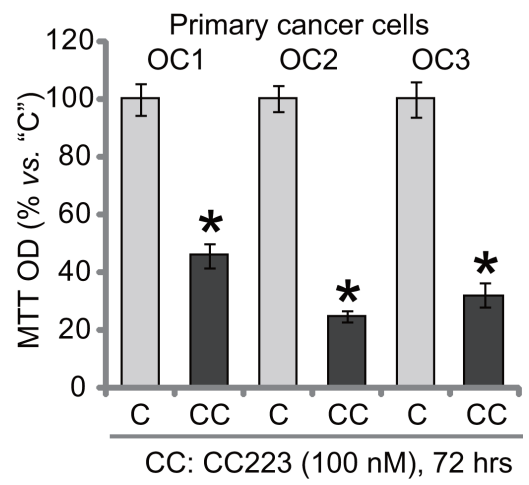

Figure 1: The effect of CC223 to ovarian cancer cell survival and proliferation. Ovarian cancer cell lines (SKOV3 and $\mathrm{CaOV} 3$ ), the ovarian surface epithelial (IOSE-80) cells or the patient-derived primary ovarian cancer cells ("OC1", "OC2" and "OC3" lines) were either left untreated ("C", same for all Figures), or treated with CC223, cells were further cultured in the CC223 conditional medium for implied time; Cell survival/death $(\mathbf{A}-\mathbf{C}, \mathbf{F})$, proliferation $(\mathbf{D})$ and cell cycle progression $(\mathbf{E})$ were tested by the listed assays. Data were presented as mean \pm standard deviation $(\mathrm{SD}, n=5)$. ${ }^{*} p<0.05 v s$. "C" group. Results in this figure were repeated three times, similar results were always obtained. 
growth, in $\mathrm{mm}^{3}$ per day, was also largely inhibited with CC223 administration (Figure 6B). Mice body weights, the indicator of mice general health, were not significantly changed by the above-mentioned $\mathrm{CC} 223$ treatments (Figure 6C). Experimental mice with CC223 treatment also didn't present with any signs of apparent toxicities, which is consistent with previous findings [18-20]. Collectively, these results confirm that $\mathrm{CC} 223$ oral administration inhibits SKOV3 tumor growth in nude mice.

\section{DISCUSSION}

Ovarian cancer remains the major cause of gynecological cancer mortality, with over 14,000 women expected to die from the disease each year $[3,4]$. mTOR signaling is frequently hyper-activated in ovarian cancer $[14,15]$. Therefore, mTOR represents an attractive oncotarget for therapeutic interventions $[14,15]$. Indeed, mTOR inhibitors are being tested in various stages of clinical development for ovarian cancer $[14,15]$.

Two mTOR complexes, mTORC1 and mTORC2, mediate mTOR signalings [8]. Rapamycin and its analogs ("rapalogs") are mTORC1 inhibitors [38-41]. The anticancer activity of these rapalogs are overall weak or moderate $[38,40]$. Rapalogs bind to FKBP12, leading to only partial inhibition of 4E-BP1 phosphorylation $[38,40]$. Also, rapalogs could not directly inhibit mTORC2, which is also important for ovarian cancer tumorigenesis and progression [42-44]. Further, mTORC1 inhibition will often lead to activation of key oncogenic cascades. Specifically, it was shown that Akt and ERK-MAPK could be activated as feedback response by rapalogs $[38,40]$. Also, the rapalogs' solubility in vivo is not satisfactory as well $[16,45]$. Therefore, recent research efforts have developed mTOR kinase inhibitors, which directly bind to the kinase domain of mTOR, leading to complete blockage of mTOR kinase activity. These inhibitors will then block both mTOR1 and mTORC2 [30, 46].

Intriguingly, our results showed that $\mathrm{CC} 223$ was even more potent in killing SKOV3 cells than the other mTOR kinase inhibitor AZD-2014 and the PI3K-AktmTOR pan inhibitor LY294002. Further, restoring mTOR activation by introduction of caAkt1 only partially inhibited CC223-induced killing of SKOV3 cells. These results
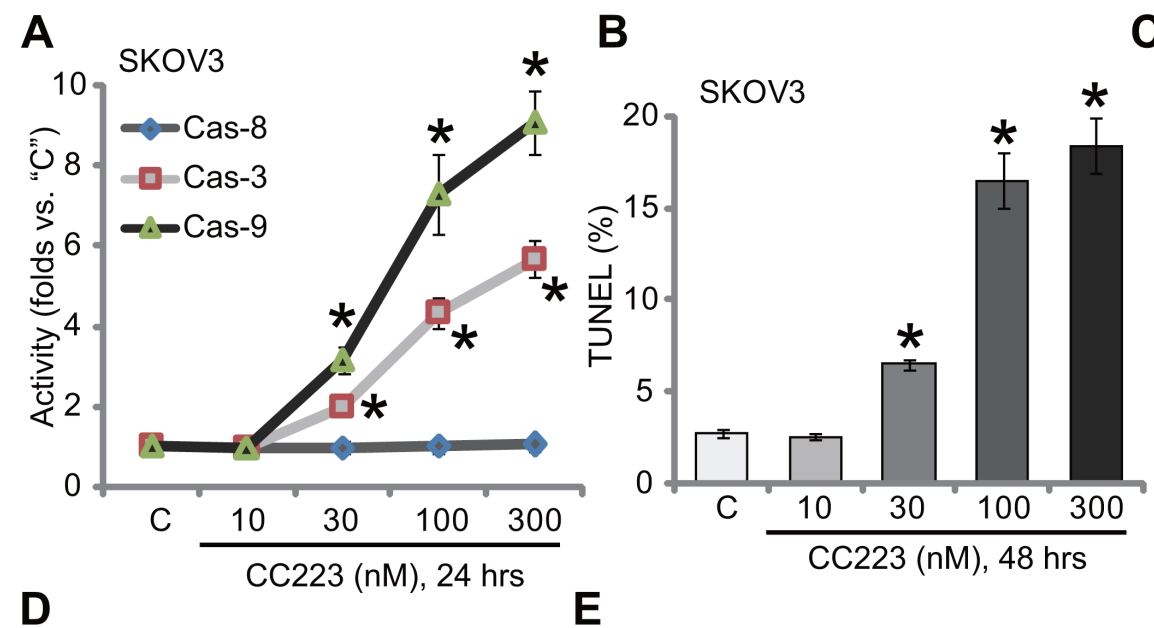

C

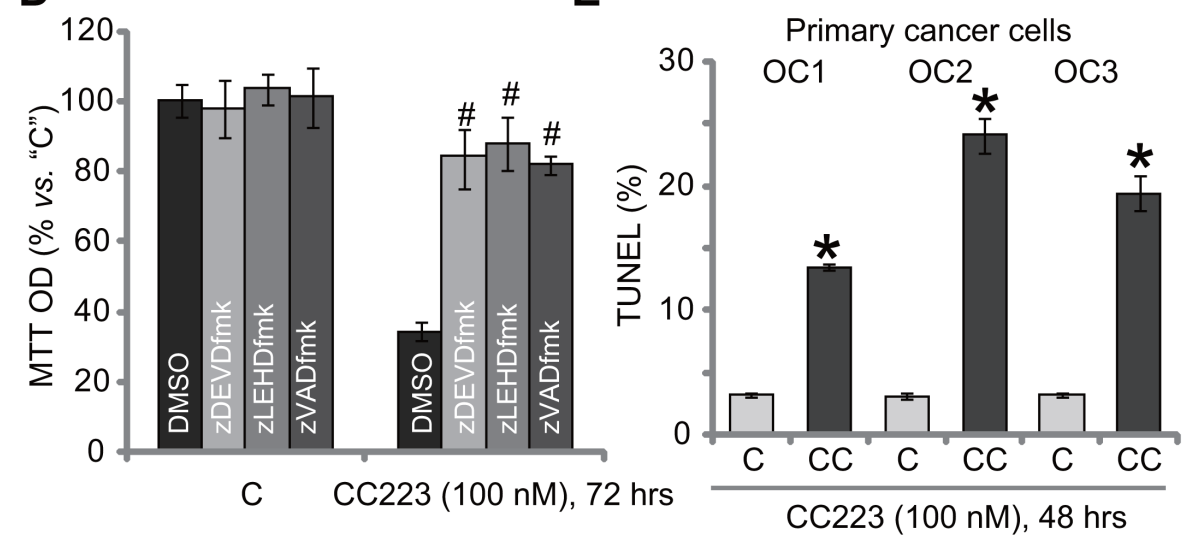

Figure 2: The effect of CC223 on ovarian cancer cell apoptosis. SKOV3 cells or the patient-derived primary ovarian cancer cells ("OC1", "OC2" and "OC3" lines) were treated with CC223 at indicated concentration, cells were further cultured; Cell apoptosis was tested by the listed assays (A-C, E); For (D), SKOV3 cells were also pre-treated for 1 hour with $50 \mu \mathrm{M}$ of caspase inhibitor z-DEVDfmk, z-LEHD-fmk or z-VAD-fmk, cell survival was tested by MTT assay. Data were presented as mean \pm standard deviation (SD, $n=5$ ). ${ }^{*} p<0.05$ vs. "C" group. $p<0.05$ vs. CC223 only (D). Results in this figure were repeated three times, similar results were always obtained. 
indicated that mTOR-independent mechanisms should also be involved in CC223-mediated anti-SKOV3 activity. Indeed, our results discovered that CC223 inhibited SphK1 and induced ROS production in SKOV3 cells. Right now, the underlying mechanisms of SphK1 inhibition and ROS production by $\mathrm{CC} 223$ were still uncertain. Yet, it should be noted that restoring mTOR activation by caAkt1 failed to reinstate SphK1 activity or to inhibit ROS production. Meanwhile, AZD-2014 and LY294002 had no significant effect on SphK1 activity nor ROS production in SKOV3 cells (Data not shown). Therefore, SphK1 inhibition and ROS production shall be the unique actions of CC223. This could explain the superior activity of this mTOR kinase inhibitor against ovarian cancer cells in vitro and in vivo. Anyhow, the associated signaling mechanisms shall require further investigations.

\section{MATERIALS AND METHODS}

\section{Chemicals and reagents}

CC223 was purchased from MCE (Shanghai, China). LY294002, AZD-2014 and rapamycin were obtained from Selleck (Shanghai, China). Caspase inhibitors, z-VAD-fmk, z-DEVD-fmk and z-LEHD-fmk, were purchased from Calbiochem (Shanghai, China). Antibodies of this study were provided by Cell Signaling Tech (Shanghai, China).

\section{Culture of established cell lines}

The two established ovarian cancer cell lines, SKOV3 and $\mathrm{CaOV} 3$, were provided by the Cell Band of Shanghai Institute of Biological Science (Shanghai, China). Cells were cultured in RPMI 1640/DMEM medium with $10 \%$ FBS. The normal ovarian epithelial cell line, IOSE-80, was provided by Dr. Fang [21]. IOSE-80 cells were cultured as described [21]. Cell culture reagents were purchased from Gibco BRL (Shanghai, China).

\section{Primary culture of human ovarian cancer cells}

Three lines of primary ovarian cancer cells ("OC1", "OC2" and "OC3") were provided by Dr. Fang [21]. Primary cancer cells were maintained in 50\% 199 medium and 50\% 105 medium (Sigma), supplemented with 15\% FBS, $4 \mathrm{ng} / \mathrm{mL}$ EGF (Sigma), $1000 \mathrm{U} / \mathrm{mL}$ penicillin, $100 \mu \mathrm{g} / \mathrm{mL}$ streptomycin, $10 \mathrm{mM}$ HEPES, $100 \mathrm{nM}$ nonessential amino acids and $1 \mathrm{mM}$ sodium pyruvate. The protocols were approved by the Ethics Review Committee

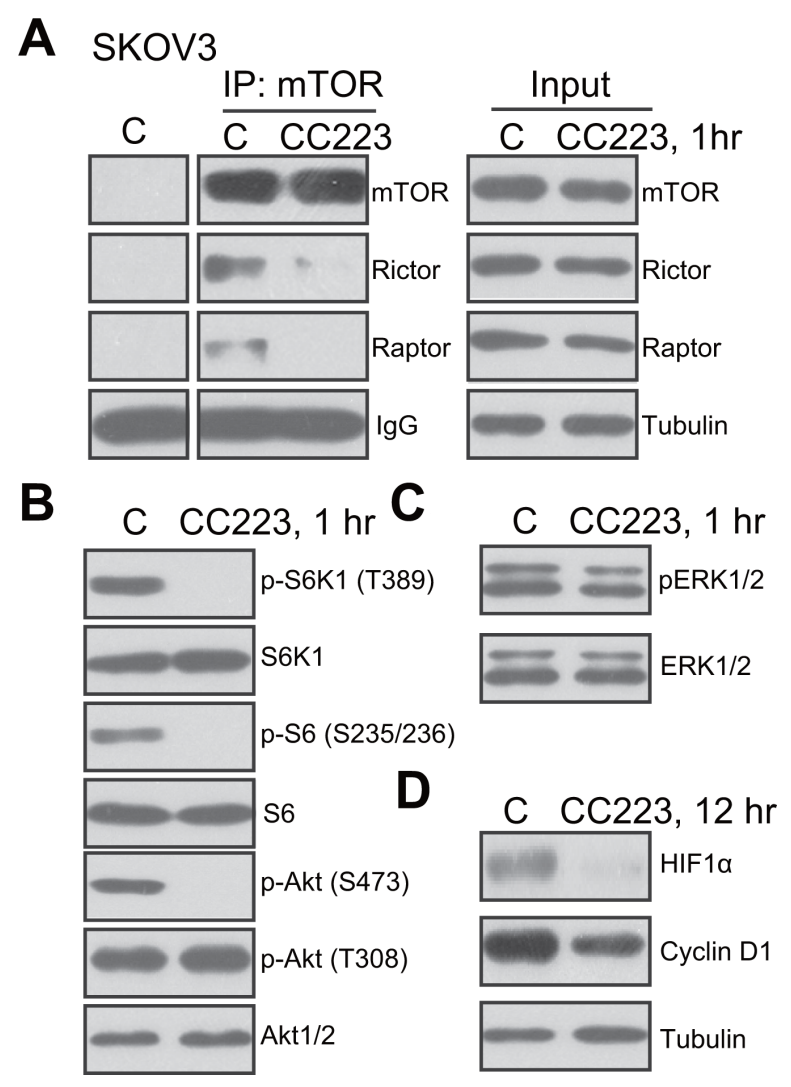

Figure 3: CC223 blocks mTORC1 and mTORC2 activation in SKOV3 cells. SKOV3 cells were treated with CC223 (100 nM), cells were further cultured for implied time, mTOR-Raptor and mTOR-Rictor assembly was tested by Co-immunoprecipitation ("Co-IP") assay (A) left panel, "IP"); Expressions of listed proteins were tested by the Western blotting assay (A, "Input" and (B-D). Results in this figure were repeated three times, similar results were always obtained. 

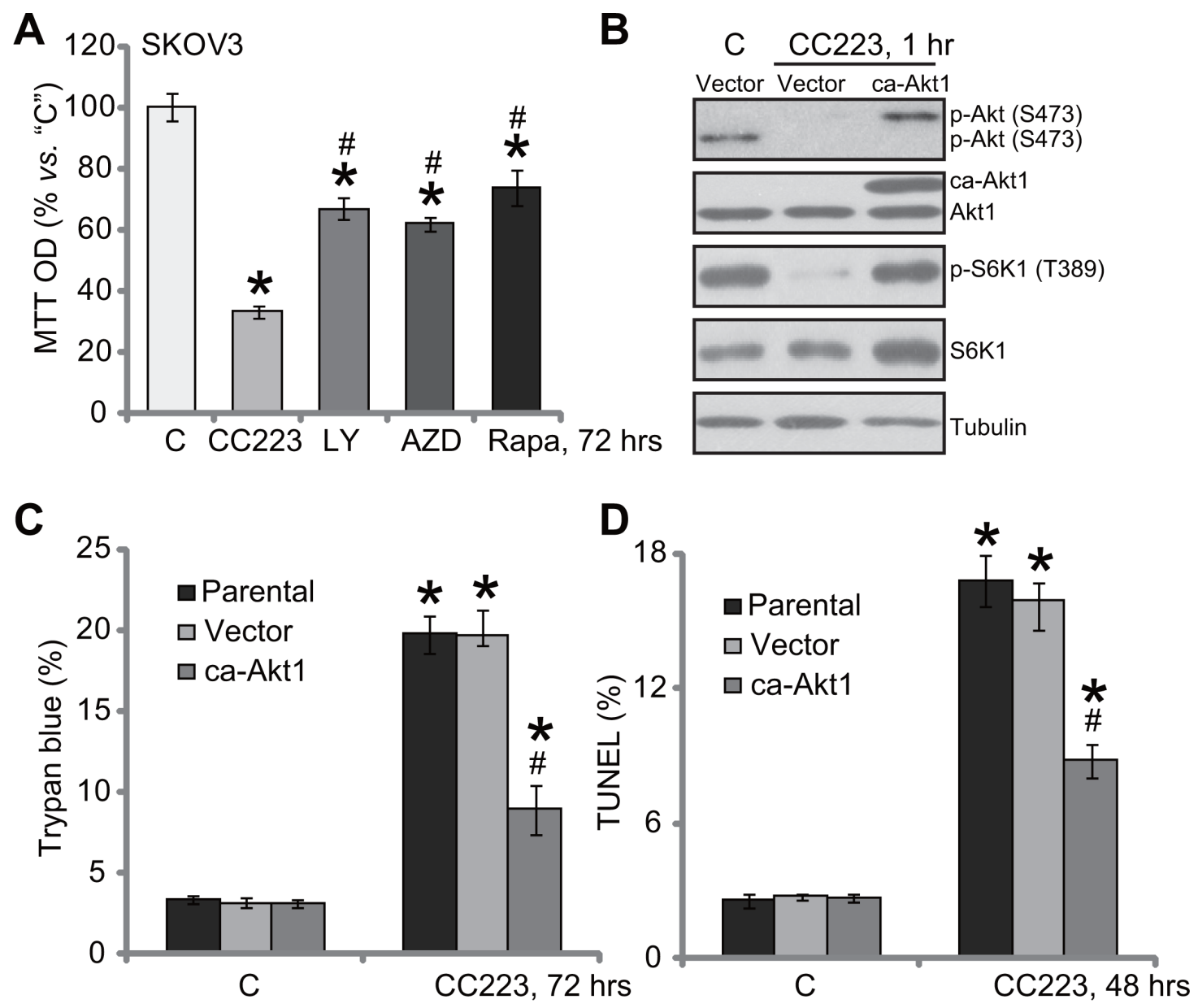

Figure 4: Restoring mTOR activation only partially inhibited CC223-induced cytotoxicity in SKOV3 cells. SKOV3 cells were treated with 100 nM CC223, LY294002 ("LY"), AZD-2014 (“AZD”) or rapamycin ("Rap") for 72 hours; Cell survival was tested by MTT assay (A). SKOV3 cells, stably expressing the constitutively-active Akt ("ca-Akt1") or empty vector, were treated with/out 100 nM of CC223 for indicted time; Expressions of listed proteins were shown (B); Cell death (Trypan blue assay, C) and apoptosis (TUNEL assay, D) were tested as well. Data were presented as mean \pm standard deviation $(\mathrm{SD}, n=5)$. "Parental" stands for parental control SKOV3 cells (C and D). ${ }^{*} p<0.05$ vs. "C" group. ${ }^{*} p<0.05$ vs. CC223 (A). ${ }^{*} p<0.05$ vs. CC223 of Vector group (C and D). Results in this figure were repeated three times, similar results were always obtained.
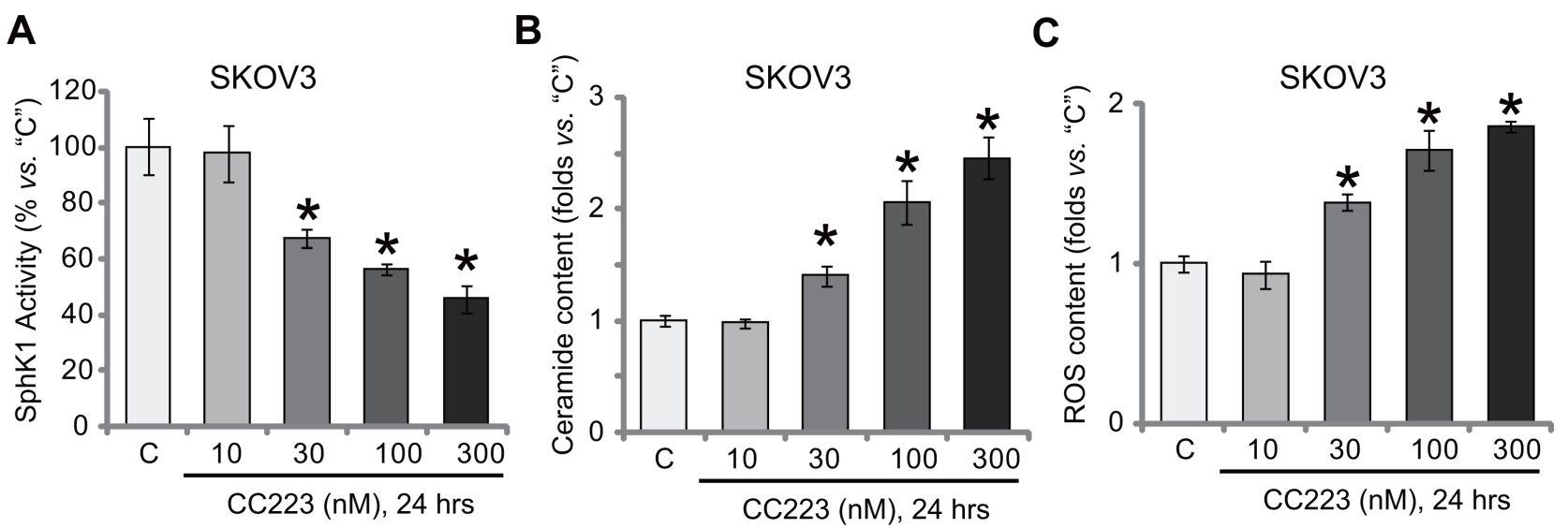

Figure 5: CC223 inhibits SphK1 and induces ROS production in SKOV3 cells. SKOV3 cells were treated with applied concentration of CC223, cells were further cultured for 24 hours; Relative SphK1 activity (A), ceramide level (B) and ROS content (C) were tested by listed assays. Data were presented as mean \pm standard deviation $(\mathrm{SD}, n=5)$. ${ }^{*} p<0.05 v s$. "C" group. Results in this figure were repeated three times, similar results were always obtained. 
of all authors institutions, and were conducted according to the principles of Declaration of Helsinki.

\section{MTT assay of cell survival}

Cells were seeded onto 96-well microtiter plates $\left(5 \times 10^{3}\right.$ per well). After the indicated treatment, cell viability was tested via MTT dye, which measures $A_{490}$ $\mathrm{nm}$ of the dissolved formazan product.

\section{Trypan blue staining assay}

Cells with the CC223 treatment were stained with trypan blue dye, which only stays into the "dead" cells. Trypan blue percentage was recorded via an automatic cell counter.

\section{Colony formation assay}

Ovarian cancer cells were maintained onto $60-\mathrm{mm}$ culture plates at 1000 cells per plate. Cells were treated with CC223 for 7 days. Afterwards, the remain surviving colonies were stained with Coomassie Blue, and were counted manually.

\section{Cell cycle analysis}

Following the CC223 treatment, ovarian cancer cells were fixed in $70 \%$ ethanol, and were stained with propidium iodide (PI). Beckman Coulter flow cytometer was then applied to FACS analysis of cell cycle. G1, S and G2M phase percentages were recorded $[47,48]$.

\section{BrdU incorporation assay}

BrdU ELISA assay kit, purchased from the Cell Signaling Tech, was applied to test cell proliferation after CC223 treatment [49]. The ELISA OD value at $450 \mathrm{nM}$ was recorded as the indicator of cell proliferation.

\section{Single-stranded DNA ELISA assay of cell apoptosis}

With CC223 treatment, single-stranded DNA (ssDNA) apoptosis ELISA (Chemicon International, Temecula, CA) assay kit was utilized to quantify cell apoptosis. The detailed protocol was described in other studies $[50,51]$.

\section{Caspase activity assay}

After CC223 treatment, $25 \mu \mathrm{g}$ of cytosolic extracts (per condition) were mixed with caspase assay buffer [21] and indicated caspase substrate: Ac-DEVD-AFC for caspase-3, Ac-LEHD-AFC for caspase-9, or AcIETD-AFC for caspase-8. After incubation, the amount of liberated AFC was tested via a spectrofluorometer (Thermo) [21].

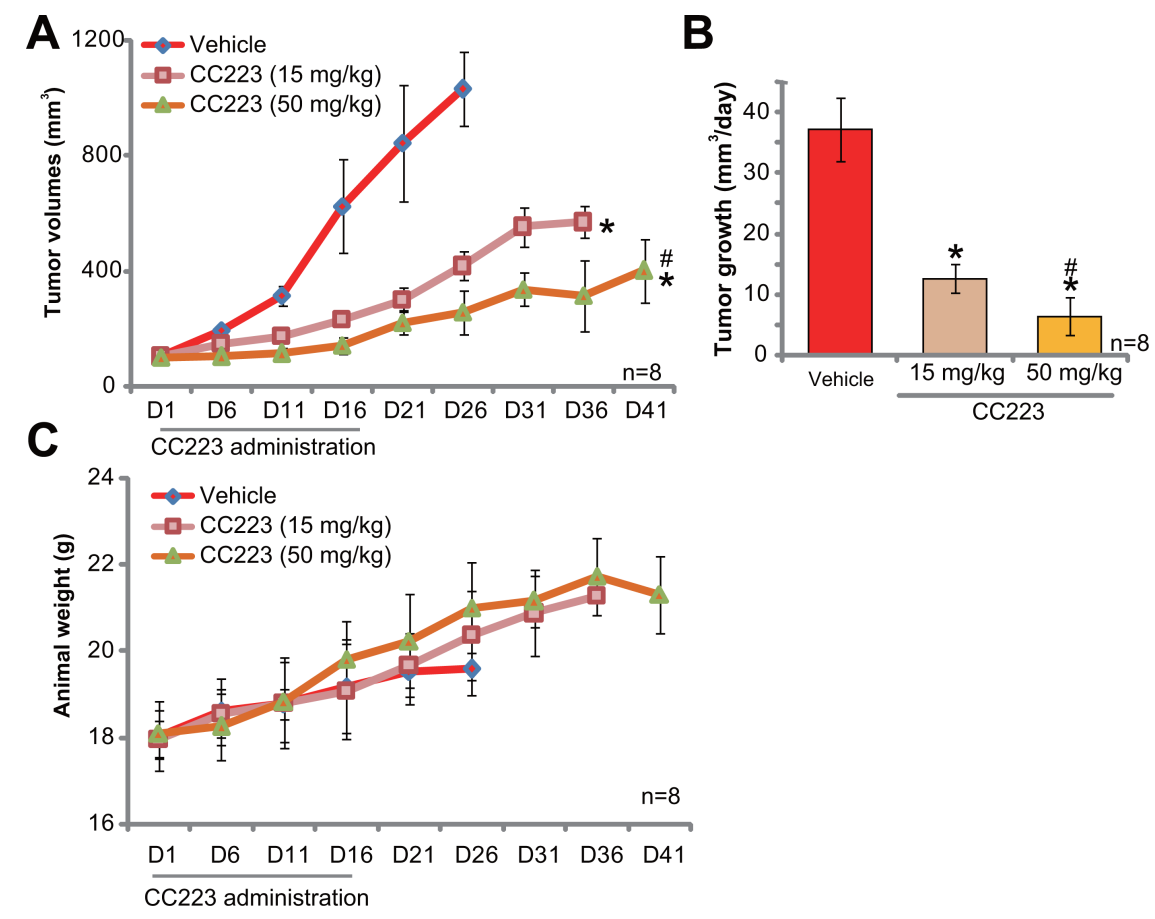

Figure 6: CC223 inhibits SKOV3 tumor growth in nude mice. Randomly-assigned nude mice ( $n=8$ per group) bearing SKOV3 xenograft tumor were administrated (via gavage) with CC223 (15 or $50 \mathrm{mg} / \mathrm{kg}$ body weight, daily) or vehicle control ("Vehicle") for 16 consecutive days; Tumor volume (A) and mice body weight (C) were recorded every 5 days for total 40 days; Estimated daily tumor growth (in $\mathrm{mm}^{3}$ per day) was also presented (B); ${ }^{*} p<0.05$ vs. "Vehicle". ${ }^{*} p<0.05$ vs. CC223 at $15 \mathrm{mg} / \mathrm{kg}$. 


\section{TUNEL assay of apoptosis}

Following CC223 treatment, cells were subjected to the TUNEL dye assay, which only stained the nuclei of apoptotic cells. Each assay analyzed at least 300 cells of same condition. TUNEL ratio (vs total nuclei) was recorded.

\section{Western blotting assay}

Protein lysates (25 $\mu \mathrm{g}$ protein/sample) were subjected to SDS-polyacrylamide gel running, and were transferred onto PVDF membranes. The blots were immunoblotted with applied primary antibodies, which were then detected with HRP-conjugated secondary antibodies. Enhanced chemiluminescence (ECL) reagents were applied to show interested bands $[52,53]$.

\section{Co-Immunoprecipitation (Co-IP) assay}

As reported previously [28], after CC223 treatment, $600 \mu \mathrm{g}$ of protein lysates per condition were pre-cleared by incubation with protein A/G Sepharose. The precleared lysate samples were then incubated with antimTOR antibody (Cell Signaling Tech) overnight. Protein $\mathrm{A} / \mathrm{G}$ Sepharose ( $30 \mu \mathrm{L}$ per treatment) was then added again to the lysates. mTOR complexes, captured by the A/G Sepharose, were washed and subjected to Western blotting assay.

\section{Constitutively active-Akt1 (caAkt1) cells}

The stable SKOV3 cells (via puromycin selection), expressing constitutively active mutant Akt1 (caAkt1) or the empty vector (Ad-GFP), were gifts from Dr. Zhang [21]. Expression of caAkt1 was verified by Western blotting assay.

\section{Assay of SphK1 activity}

SphK1 activity assay was described previously $[21,22]$. Briefly, after the applied treatment, $25 \mu \mathrm{g}$ cell lysates per condition were incubated with D-erythrosphingosine containing medium [21]. The reaction was terminated by $\mathrm{HCl}(1 \mathrm{~N})$ and chloroform/ methanol/HCl (100:200:1, v/v) buffer [21]. Afterwards, the solution were subjected to vigorous vortex, phases were separated. Radio-labeled sphingosine-1-phosphate (S1P) was separated by 60 thin-layer chromatography (TLC) on silica gel G60-plates with chloroform/acetone/ methanol/acetic acid/water (10:4:3:2:1, v/v) as solvent. The phosphate incorporation was then quantified via a scintillation counter (LS-6500, Beckman, Shanghai, China) [54]. The SphK1 activity was valued as pmol/ hour/g protein, and was always normalized to the control level.

\section{Ceramide content test}

The intracellular ceramide content was analyzed by the previously described protocol [55], which was valued as fmol by nmol of phospholipid. Ceramide content in the CC223-treated cells was always normalized to that of untreated control group.

\section{Assay of cellular reactive oxygen species (ROS) content}

After CC223 treatment, ROS level was measured through the DCFH-DA fluorescent dye (Invitrogen) assay. The detailed protocol was described previously [56, 57]. Briefly, cells were incubated with $10 \mu \mathrm{M}$ of DCFH-DA for $30 \mathrm{~min}$, and were analyzed for fluorescence via the Fluorescence Microplate Reader (Synergy 2, BioTek, Winooski, VT).

\section{SKOV3 xenograft assay}

Female nude mice (5-6 weeks old, 17.5-18.5 grams) were injected s.c. with SKOV3 cells $\left(5 \times 10^{6}\right.$ per mouse, in Matrigel). When tumors reached at around $100 \mathrm{~mm}^{3}$ in volume, mice were randomized into three groups, and daily treatment with vehicle, $10 \mathrm{mg} / \mathrm{kg}$ or $50 \mathrm{mg} / \mathrm{kg}$ of CC223 (p.o., daily, for 16 days). Tumor volume was calculated via the formula: Volume $\left(\mathrm{mm}^{3}\right)=\left(d^{2} \times D\right) / 2$, in which $d$ and $D$ were the shortest and the longest tumor diameter. All animal experiments were approved by Institutional Animal Care and Use Committee (IACUC) and NIH animal regulations.

\section{Statistical analysis}

Data were analyzed by SPSS software (Version 17.0). ANOVA was performed for comparison across treatment regimes. Significance was set at $p<0.05$ for all comparisons.

\section{Authors' contribution}

All the listed authors in the study carried out the experiments, participated in the design of the study and performed the statistical analysis, conceived of the study, and helped to draft the manuscript.

\section{ACKNOWLEDGMENTS AND FUNDING}

This study was supported by the Natural Science Foundation Projects of Shandong Province (ZR2012HL002, ZR2015HL022), Science and Technology development Projects of Jining City (Jikezi [2015]57-121, NO.2013jnwk132) and by Open Foundation Project of State Key Laboratory of Environmental chemistry and Ecotoxicology (KF2014-12). 


\section{CONFLICTS OF INTEREST}

The authors declare no conflicts of interests.

\section{REFERENCES}

1. Vaughan S, Coward JI, Bast RC Jr, Berchuck A, Berek JS, Brenton JD, Coukos G, Crum CC, Drapkin R, Etemadmoghadam D, Friedlander M, Gabra H, Kaye SB, et al. Rethinking ovarian cancer: recommendations for improving outcomes. Nat Rev Cancer. 2011; 11:719-725.

2. Kipps E, Tan DS, Kaye SB. Meeting the challenge of ascites in ovarian cancer: new avenues for therapy and research. Nat Rev Cancer. 2013; 13:273-282.

3. Siegel RL, Miller KD, Jemal A. Cancer Statistics, 2017. CA Cancer J Clin. 2017; 67:7-30.

4. Siegel RL, Miller KD, Jemal A. Cancer statistics, 2016. CA Cancer J Clin. 2016; 66:7-30.

5. Markman M. Chemotherapy: limited use of the intraperitoneal route for ovarian cancer-why? Nat Rev Clin Oncol. 2015; 12:628-630.

6. Nick AM, Coleman RL, Ramirez PT, Sood AK. A framework for a personalized surgical approach to ovarian cancer. Nat Rev Clin Oncol. 2015; 12:239-245.

7. Coleman RL, Monk BJ, Sood AK, Herzog TJ. Latest research and treatment of advanced-stage epithelial ovarian cancer. Nat Rev Clin Oncol. 2013; 10:211-224.

8. Saxton RA, Sabatini DM. mTOR Signaling in Growth, Metabolism, and Disease. Cell. 2017; 168:960-976.

9. Zhu YR, Zhou XZ, Zhu LQ, Yao C, Fang JF, Zhou F, Deng XW, Zhang YQ. The anti-cancer activity of the mTORC1/2 dual inhibitor XL388 in preclinical osteosarcoma models. Oncotarget. 2016; 7:49527-49538. https://doi. org/10.18632/oncotarget.10389.

10. Zhang G, Wang C, Sun M, Li J, Wang B, Jin C, Hua P, Song G, Zhang Y, Nguyen LL, Cui R, Liu R, Wang L, Zhang X. Cinobufagin inhibits tumor growth by inducing intrinsic apoptosis through AKT signaling pathway in human nonsmall cell lung cancer cells. Oncotarget. 2016; 7:28935-28946. https://doi.org/10.18632/oncotarget.7898.

11. Wei L, Chintala S, Ciamporcero E, Ramakrishnan S, Elbanna M, Wang J, Hu Q, Glenn ST, Murakami M, Liu L, Gomez EC, Sun Y, Conroy J, et al. Genomic profiling is predictive of response to cisplatin treatment but not to PI3K inhibition in bladder cancer patient-derived xenografts. Oncotarget. 2016; 7:76374-76389. https://doi.org/10.18632/ oncotarget. 13062 .

12. Chen MB, Zhou ZT, Yang L, Wei MX, Tang M, Ruan TY, Xu JY, Zhou XZ, Chen G, Lu PH. KU-0060648 inhibits hepatocellular carcinoma cells through DNA-PKcs-dependent and DNA-PKcs-independent mechanisms. Oncotarget. 2016; 7:17047-17059. https://doi.org/10.18632/oncotarget.7742.

13. Altomare DA, Wang HQ, Skele KL, De Rienzo A, KleinSzanto AJ, Godwin AK, Testa JR. AKT and mTOR phosphorylation is frequently detected in ovarian cancer and can be targeted to disrupt ovarian tumor cell growth. Oncogene. 2004; 23:5853-5857.

14. Mabuchi S, Kuroda H, Takahashi R, Sasano T. The PI3K/ $\mathrm{AKT} / \mathrm{mTOR}$ pathway as a therapeutic target in ovarian cancer. Gynecol Oncol. 2015; 137:173-179.

15. Li H, Zeng J, Shen K. PI3K/AKT/mTOR signaling pathway as a therapeutic target for ovarian cancer. Arch Gynecol Obstet. 2014; 290:1067-1078.

16. Dancey J. mTOR signaling and drug development in cancer. Nat Rev Clin Oncol. 2010; 7:209-219.

17. Sabatini DM. mTOR and cancer: insights into a complex relationship. Nat Rev Cancer. 2006; 6:729-734.

18. Mortensen DS, Fultz KE, Xu S, Xu W, Packard G, Khambatta G, Gamez JC, Leisten J, Zhao J, Apuy J, Ghoreishi K, Hickman M, Narla RK, et al. CC-223, a Potent and Selective Inhibitor of mTOR Kinase: In Vitro and In Vivo Characterization. Mol Cancer Ther. 2015; 14:1295-1305.

19. Mortensen DS, Perrin-Ninkovic SM, Shevlin G, Zhao J, Packard G, Bahmanyar S, Correa M, Elsner J, Harris R, Lee BG, Papa P, Parnes JS, Riggs JR, et al. Discovery of mammalian target of rapamycin (mTOR) kinase inhibitor CC-223. J Med Chem. 2015; 58:5323-5333.

20. Bendell JC, Kelley RK, Shih KC, Grabowsky JA, Bergsland E, Jones S, Martin T, Infante JR, Mischel PS, Matsutani T, Xu S, Wong L, Liu Y, et al. A phase I dose-escalation study to assess safety, tolerability, pharmacokinetics, and preliminary efficacy of the dual mTORC1/mTORC2 kinase inhibitor CC-223 in patients with advanced solid tumors or multiple myeloma. Cancer. 2015; 121:3481-3490.

21. Zhang D, Xia H, Zhang W, Fang B. The anti-ovarian cancer activity by WYE-132, a mTORC1/2 dual inhibitor. Tumour Biol. 2016; 37:1327-1336.

22. Yang YL, Ji C, Cheng L, He L, Lu CC, Wang R, Bi ZG. Sphingosine kinase-1 inhibition sensitizes curcumininduced growth inhibition and apoptosis in ovarian cancer cells. Cancer Sci. 2012; 103:1538-1545.

23. Ying L, Chunxia Y, Wei L. Inhibition of ovarian cancer cell growth by a novel TAK1 inhibitor LYTAK1. Cancer Chemother Pharmacol. 2015; 76:641-650.

24. Wen $X$, Lin ZQ, Liu B, Wei YQ. Caspase-mediated programmed cell death pathways as potential therapeutic targets in cancer. Cell Prolif. 2012; 45:217-224.

25. Broker LE, Kruyt FA, Giaccone G. Cell death independent of caspases: a review. Clin Cancer Res. 2005; 11:3155-3162.

26. Ali SM, Sabatini DM. Structure of S6 kinase 1 determines whether raptor-mTOR or rictor-mTOR phosphorylates its hydrophobic motif site. J Biol Chem. 2005; 280:19445-19448.

27. Sarbassov DD, Ali SM, Kim DH, Guertin DA, Latek RR, Erdjument-Bromage H, Tempst P, Sabatini DM. Rictor, a novel binding partner of mTOR, defines a rapamycininsensitive and raptor-independent pathway that regulates the cytoskeleton. Curr Biol. 2004; 14:1296-1302. 
28. Zheng B, Mao JH, Qian L, Zhu H, Gu DH, Pan XD, Yi F, Ji DM. Pre-clinical evaluation of AZD-2014, a novel mTORC1/2 dual inhibitor, against renal cell carcinoma. Cancer Lett. 2015; 357:468-475.

29. Jiang SJ, Wang S. Dual targeting of $\mathrm{mTORC} 1$ and $\mathrm{mTORC} 2$ by INK-128 potently inhibits human prostate cancer cell growth in vitro and in vivo. Tumour Biol. 2015; 36:8177-8184.

30. Gomez-Pinillos A, Ferrari AC. mTOR signaling pathway and mTOR inhibitors in cancer therapy. Hematol Oncol Clin North Am. 2012; 26:483-505, vii.

31. Kang SA, Pacold ME, Cervantes CL, Lim D, Lou HJ, Ottina K, Gray NS, Turk BE, Yaffe MB, Sabatini DM. mTORC1 phosphorylation sites encode their sensitivity to starvation and rapamycin. Science. 2013; 341:1236566.

32. Pike KG, Malagu K, Hummersone MG, Menear KA, Duggan HM, Gomez S, Martin NM, Ruston L, Pass SL, Pass M. Optimization of potent and selective dual mTORC1 and mTORC2 inhibitors: the discovery of AZD8055 and AZD2014. Bioorg Med Chem Lett. 2013; 23:1212-1216.

33. Brunn GJ, Williams J, Sabers C, Wiederrecht G, Lawrence JC Jr, Abraham RT. Direct inhibition of the signaling functions of the mammalian target of rapamycin by the phosphoinositide 3-kinase inhibitors, wortmannin and LY294002. EMBO J. 1996; 15:5256-5267.

34. Zou Y, Fan G, Wang X. Pre-clinical assessment of A-674563 as an anti-melanoma agent. Biochem Biophys Res Commun. 2016; 477:1-8.

35. Zhang H, Wang Q, Zhao Q, Di W. MiR-124 inhibits the migration and invasion of ovarian cancer cells by targeting SphK1. J Ovarian Res. 2013; 6:84.

36. Shida D, Takabe K, Kapitonov D, Milstien S, Spiegel S. Targeting SphK1 as a new strategy against cancer. Curr Drug Targets. 2008; 9:662-673.

37. Vadas M, Xia P, McCaughan G, Gamble J. The role of sphingosine kinase 1 in cancer: oncogene or non-oncogene addiction? Biochim Biophys Acta. 2008; 1781:442-447.

38. Zhou HY, Huang SL. Current development of the second generation of mTOR inhibitors as anticancer agents. Chin J Cancer. 2012; 31:8-18.

39. Zaytseva YY, Valentino JD, Gulhati P, Evers BM. mTOR inhibitors in cancer therapy. Cancer Lett. 2012; 319:1-7.

40. Vilar E, Perez-Garcia J, Tabernero J. Pushing the envelope in the mTOR pathway: the second generation of inhibitors. Mol Cancer Ther. 2011; 10:395-403.

41. Vanhaesebroeck B, Stephens L, Hawkins P. PI3K signalling: the path to discovery and understanding. Nat Rev Mol Cell Biol. 2012; 13:195-203.

42. Kennedy BK, Lamming DW. The Mechanistic Target of Rapamycin: The Grand ConducTOR of Metabolism and Aging. Cell Metab. 2016; 23:990-1003.

43. Ashworth RE, Wu J. Mammalian target of rapamycin inhibition in hepatocellular carcinoma. World J Hepatol. 2014; 6:776-782.
44. Monaco AP. The role of mTOR inhibitors in the management of posttransplant malignancy. Transplantation. 2009; 87:157-163.

45. Liu Q, Thoreen C, Wang J, Sabatini D, Gray NS. mTOR Mediated Anti-Cancer Drug Discovery. Drug Discov Today Ther Strateg. 2009; 6:47-55.

46. Sun SY. mTOR kinase inhibitors as potential cancer therapeutic drugs. Cancer Lett. 2013; 340:1-8.

47. Zhao H, Guo Y, Li S, Han R, Ying J, Zhu H, Wang Y, Yin L, Han Y, Sun L, Wang Z, Lin Q, Bi X, et al. A novel anticancer agent Icaritin suppresses hepatocellular carcinoma initiation and malignant growth through the IL-6/Jak2/ Stat3 pathway. Oncotarget. 2015; 6:31927-31943. https:// doi.org/10.18632/oncotarget.5578.

48. Grillo E, Ravelli C, Corsini M, Ballmer-Hofer K, Zammataro L, Oreste P, Zoppetti G, Tobia C, Ronca R, Presta M, Mitola S. Monomeric gremlin is a novel vascular endothelial growth factor receptor-2 antagonist. Oncotarget. 2016; 7:35353-68. https://doi.org/10.18632/ oncotarget.9286.

49. Zhang YM, Zhang ZQ, Liu YY, Zhou X, Shi XH, Jiang Q, Fan DL, Cao C. Requirement of Galphai1/3-Gab1 signaling complex for keratinocyte growth factor-induced PI3KAKT-mTORC1 activation. J Invest Dermatol. 2015; 135:181-191.

50. Xu L, Tu Z, Xu G, Wang Y, Pan W, Zhan X, Luo Q, Huang Y, Chen J, Huang A. Epirubicin directly promotes hepatitis $\mathrm{B}$ virus (HBV) replication in stable $\mathrm{HBV}$ expressing cell lines: a novel mechanism of HBV reactivation following anticancer chemotherapy. Mol Med Rep. 2014; 9:1345-1350.

51. Renaud J, Bournival J, Zottig X, Martinoli MG. Resveratrol protects DAergic PC12 cells from high glucose-induced oxidative stress and apoptosis: effect on p53 and GRP75 localization. Neurotox Res. 2014; 25:110-123.

52. Wang HC, Zhang T, Kuerban B, Jin YL, Le W, Hara H, Fan DS, Wang YJ, Tabira T, Chui DH. Autophagy is involved in oral $\mathrm{rAAV} / \mathrm{Abeta}$ vaccine-induced Abeta clearance in APP/PS1 transgenic mice. Neurosci Bull. 2015; 31:491-504.

53. Jia J, Le W. Molecular network of neuronal autophagy in the pathophysiology and treatment of depression. Neurosci Bull. 2015; 31:427-434.

54. Altura BM, Shah NC, Shah GJ, Zhang A, Li W, Zheng T, Perez-Albela JL, Altura BT. Short-term Mg deficiency upregulates protein kinase $\mathrm{C}$ isoforms in cardiovascular tissues and cells; relation to NF-kB, cytokines, ceramide salvage sphingolipid pathway and PKC-zeta: hypothesis and review. Int J Clin Exp Med. 2014; 7:1-21.

55. Gong L, Yang B, Xu M, Cheng B, Tang X, Zheng $\mathrm{P}$, Jing Y, Wu GJ. Bortezomib-induced apoptosis in cultured pancreatic cancer cells is associated with ceramide production. Cancer Chemother Pharmacol. 2014; 73:69-77.

56. Liu W, Mao L, Ji F, Chen F, Hao Y, Liu G. Targeted activation of AMPK by GSK621 ameliorates $\mathrm{H} 2 \mathrm{O} 2$-induced 
damages in osteoblasts. Oncotarget. 2017; 8:10543-10552. https://doi.org/10.18632/oncotarget.14454.

57. Guo S, Mao L, Ji F, Wang S, Xie Y, Fei H, Wang XD. Activating AMP-activated protein kinase by an alpha1 selective activator compound 13 attenuates dexamethasoneinduced osteoblast cell death. Biochem Biophys Res Commun. 2016; 471:545-552. 